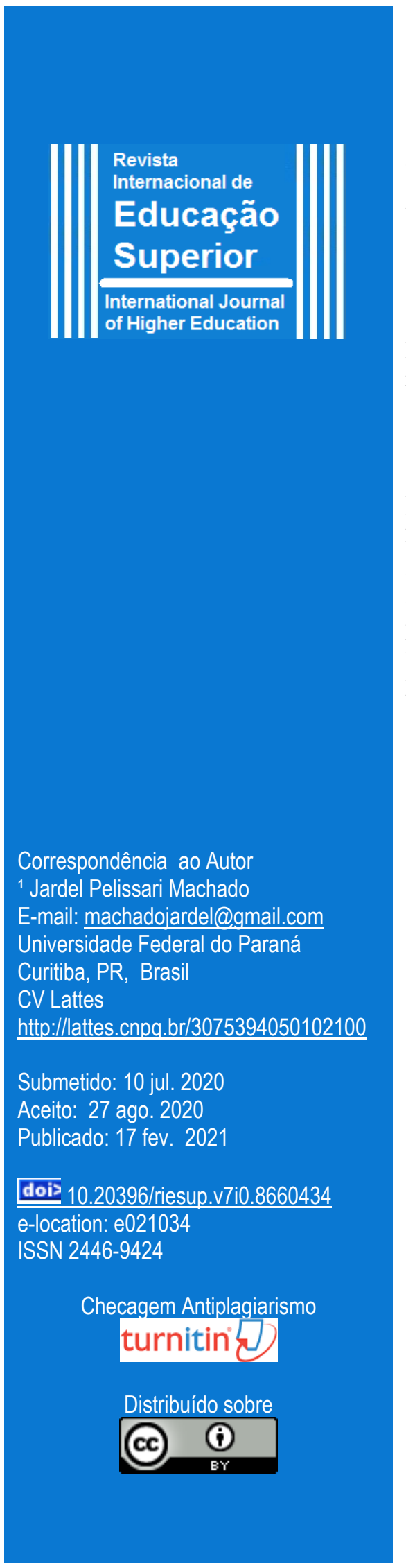

\title{
(In)Visibilizados e (in)Dizíveis da/na Vida Estudantil na Univers/cidade
}

Jardel Pelissari Machado ${ }^{\text {(DD }}$ http://orcid.org/0000-0001-9840-8992

Andrea Vieira Zanella2 (iD) http://orcid.org/0000-0001-8949-0605

${ }^{1}$ Universidade Federal do Paraná, ${ }^{2}$ Universidade Federal de Santa Catarina

\section{RESUMO}

Este texto tem por objetivo analisar enunciados verbais e imagéticos, respostas de estudantes às vozes sociais que produzem os espaçotempos, condições e possibilidades da/na vida acadêmica universitária e que expressam alguma forma de sofrimento. Esses enunciados, diálogos (transcritos) e fotografias, foram produzidos no contexto de Oficinas de Fotografia, que compuseram uma pesquisa-intervenção de doutorado em psicologia, por estudantes de graduação (num total de 16 participantes) de uma universidade federal brasileira. Discutimos sobre esses enunciados como produto/reflexo de exclusão no contexto acadêmico universitário que é, na maioria das vezes, silenciado e invisibilizado em meio a lógicas de produtividade, custos, rankings, entre outras. Concluímos sobre a necessidade de construção de espaços em que as vozes das/os estudantes possam circular, ser ouvidas/lidas, para que possam auxiliar, de forma efetiva, na construção das universidades e das condições e possibilidades da vida acadêmica.

\section{PALAVRAS-CHAVE}

Universidade. Estudantes. Exclusão escolar. Fotografia. Análise de discurso. 


\title{
(Un)Visible and (Un)Speakable from/of Student Life at the Univers/Cities
}

\begin{abstract}
This text aims to analyze verbal and image statements, student responses to social voices that produce the spacetimes, conditions and possibilities of / in university academic life and that express some form of suffering. These statements, dialogues (transcripts) and photographs, were produced in the context of Photography Workshops, which comprised a doctoral research-intervention in psychology, by undergraduate students (a total of 16 participants) of a Brazilian federal university. We discussed these statements as a product/reflection of exclusion in the academic university context, which is, in most cases, silenced and invisible in the midst of logics of productivity, costs, rankings, among others. We conclude on the need to build spaces were the voices of the students can circulate, be heard/read, so that they can effectively assist in the construction of universities and the conditions and possibilities of academic life.
\end{abstract}

\section{KEYWORDS}

University. Students. School exclusion. Photography. Discourse analysis.

\section{(En)Visibilizadas y (In)Decíble de/en la Vida del Estudiante en la Univers/ciudad}

\section{RESUMEN}

Este texto tiene como objetivo analizar los enunciados verbales e imaginarios, las respuestas de los estudiantes a las voces sociales que producen los espacios-tiempos, condiciones y posibilidades de / en la vida académica universitaria y que expresan alguna forma de sufrimiento. Estas declaraciones, diálogos (transcritos) y fotografías, fueron producidos en el contexto de Talleres de Fotografía, que comprendieron una investigaciónintervención doctoral en psicología, por estudiantes de pregrado (en un total de 16 participantes) de una universidad federal brasileña. Discutimos estas afirmaciones como producto / reflejo de exclusión en el contexto académico académico, que en la mayoría de los casos es silenciado e invisible en medio de lógicas de productividad, costos, rankings, entre otras. Concluimos sobre la necesidad de construir espacios en los que las voces de los estudiantes puedan circular, ser escuchadas / leídas, para que puedan ayudar efectivamente en la construcción de universidades y las condiciones y posibilidades de la vida académica.

PALABRAS CLAVE

Universidad. Estudiantes. Exclusión escolar. Fotografía. Análisis del discurso. 


\section{Introdução}

A produção histórica das instituições de educação se dá em meio a tramas discursivas tecidas nas tensões entre diversas vozes que, como efeito, tem produzido, organizado e possibilitado pensabilidades, dizibilidades, sensibilidades - enfim, produzido subjetividades. A universidade, compondo o campo da educação, do mesmo modo, é também atravessada e constituída por essas tensões. Nela, a vida estudantil resta e emerge como produto, refletindo e refratando esses mesmos processos históricos de suas constituições.

Com foco na vida estudantil universitária, realizamos um estudo com o objetivo e investigar os diálogos que as/os ${ }^{1}$ estudantes tecem em seus cotidianos na e para com a UniverS/Cidade ${ }^{2}$. Para tal, realizamos uma pesquisa junto a estudantes de graduação de uma universidade federal do sul do Brasil, na qual trabalhamos com Oficinas de Fotografia mobile $^{3}$. Nas Oficinas discutimos com as/os estudantes sobre: o cotidiano na UniverS/Cidade; a organização da vida, dos espaços e tempos; a constituição do olhar e as possibilidades de visibilidades; a composição e processos de produção de fotografias. Nessas Oficinas, as/os estudantes produziram fotografias sobre seus cotidianos na instituição, as quais foram analisadas como imagens-enunciados que visibilizam o modo como percebem o contexto do qual participam e suas vivências na universidade, constituindo-se como respostas às/nas tramas discursivas que constituem as instituições e as potencialidades e possibilidades da vida estudantil.

Falas, diálogos e imagens que emergiram no contexto das Oficinas possibilitaram a visualização e que fossem ouvidas dimensões da vida estudantil no contexto universitário, as quais têm sido, comumente, veladas e/ou silenciadas. Uma dessas dimensões, sobre a qual nos debruçamos neste texto, expressa-se, muitas vezes, como sofrimento que é vivenciado por estudantes que, incluídos nessas instituições de ensino, precisam dar conta de uma série de condições para manterem-se nelas e concluírem os seus cursos.

Tomando enunciados das/os estudantes no contexto das Oficinas que expressam sofrimento a partir do dialogismo (BAKHTIN, 2017, 2018; VOLOCHÍNOV, 2013; 2017) que constitui as tensões e arenas discursivas da educação superior pública brasileira, este estudo tem por objetivo analisar enunciados verbais e imagéticos que emergiram como resposta de estudantes às vozes sociais que instituem espaçotempos, condições e possibilidades da/na vida acadêmica.

\footnotetext{
${ }^{1}$ Tomamos, neste texto, essa forma de grafia "as/os", com o artigo feminino em primeiro lugar, em atenção e respeito às mulheres estudantes universitárias que são a maioria nas instituições de ensino superior, conforme Relatório do INEP (2018).

${ }^{2}$ UniverS/Cidade é a escrita que criamos para nos referirmos à instituição e a cidade nas quais o estudo foi realizado. Escrita dessa forma, representa a cidade e a instituição de ensino superior (tão grande quanto uma cidade e também fragmentada e compondo-a).

${ }^{3}$ Mobile refere-se ao celular. As oficinas foram conduzidas pensando na produção de fotografias com câmeras disponíveis nesses aparelhos por serem dispositivos que a maioria da população acadêmica tem acesso (diferentemente de uma câmera fotográfica) e também por sua praticidade de transporte e para a produção de imagens sobre o cotidiano (que eram o foco das oficinas). Todas e todos as/os participantes utilizaram seus celulares durante as oficinas, à exceção e uma, que possuía uma câmera fotográfica e que preferiu trabalhar com
} ela. 


\section{Universidade, Economia e Tempo}

Os processos de transformações das universidades vêm sendo analisados há tempos no que se refere aos impactos de lógicas econômicas e organismos internacionais que promovem a transformação da educação de direito em serviço (CHAUÍ, 2001, 2003, 2016; SANTOS, 2001, 2010). Essa transformação tem produzido cotidianos institucionais cada vez mais marcados por metas e indicadores de desempenho, sendo a qualidade da educação mensurada por quantidade, tempo e custo.

Estudos recentes têm demonstrado a manutenção dessa ligação da expansão da educação superior brasileira em meio ao processo de mundialização do capital, com a adoção, pelo Estado, de políticas liberais referentes ao financiamento da educação, a políticas de competitividade, de patentes e de direitos autorais, educação à distância e mercantilização da educação (COSTA; GOULART, 2018; MANCEBO; SILVA JÚNIOR; SCHUGURENSKY, 2016; SIGAHI; SALTORATO, 2018). A política educacional fica reduzida, pois, a um subconjunto da política econômica, produzindo uma cultura de performatividade na qual o êxito é mensurado por flexibilidade, adaptabilidade, eficiência, desempenho e competitividade (SIGAHI; SALTORATO, 2018). Ao mesmo passo em que essas políticas tem possibilitado o acesso à educação, conforme dados de matrículas (INEP, 2018), a massificação na formação superior tem mostrado sua face mais perversa: não apenas a produção de números, mas a formação de trabalhadoras/es voltados à empregabilidade, mais produtivos, flexíveis, polivalentes e adaptáveis às novas formas de organização e gestão do trabalho, com grande disposição para suportarem a intensificação e precarização das condições de trabalho e predispostos a aceitarem e assumirem riscos (MANCEBO; SILVA JÚNIOR; SCHUGURENSKY, 2016; SIGAHI; SALTORATO, 2018).

Frente a esse contexto, lemos, seja em trabalhos acadêmicos acessíveis nas bases de dados bibliográficos ou em mídias jornalísticas que os divulgam, dados estatísticos referentes a adoecimento, estresse, desgaste e/ou sofrimento mental em estudantes de graduação e pósgraduação (ESPIRIDIÃO et al., 2013; GRANER; RAMOS-CERQUEIRA, 2017; MATTA; LEBRÃO; HELENO, 2017). Ao serem abordadas essas questões, estudos tem concluído sobre a necessidade de ações e políticas institucionais. Essas, porém, não tem como foco as lógicas que produzem as condições nas quais o sofrimento/adoecimento emergem como produto, mas sim a necessidade de adaptação das/os estudantes.

Os estudos desenvolvidos por Matta, Lebrão e Heleno (2017) e Yosetake et. al. (2018), referem-se ao tempo como excesso de carga horária, ou falta de tempo livre, porém sem discutir o que produz essas condições. Em Basso et. al. (2013), as pesquisadoras relatam sobre trabalho de oficinas de organização de tempo e métodos de estudo que construíram e que foram realizadas com estudantes de graduação de uma universidade federal. Apontam como motivadores, relatados pelas/os estudantes, quanto à procura pelas oficinas: "dificuldades para organizar o tempo; necessidade de melhor organizar estudos; problemas de focalização da atenção; necessidade de aprender a se disciplinar; baixo desempenho 
acadêmico; maximizar o seu rendimento; buscar equilíbrio entre a vida acadêmica e a vida pessoal" (BASSO et al., 2013, p. 281). Ao focar o "desempenho acadêmico", o estudo, porém, sugere apenas ações referentes à adaptabilidade da/o estudante, sem analisar a lógicas que sustentam o funcionamento da instituição. O mesmo ocorre em Oliveira et. al. (2016), ao relatarem sobre Oficinas realizadas com estudantes quanto a organização do tempo. No artigo, concluem que psicólogas/os que trabalham nas universidades podem "replicar essas oficinas ou, ainda, utilizar as informações e técnicas relatadas em atendimentos individuais ou grupais com foco na adaptação acadêmica, no caso de estudantes de graduação, ou na produtividade, no caso de estudantes de pós-graduação e professores pesquisadores" (OLIVEIRA et al., 2016, p. 231).

Conclusões semelhantes são apresentadas em outros estudos: construção de formas de auxílio psicológico a estudantes ou aumento do número de profissionais para esse fim (MATTA; LEBRÃO; HELENO, 2017; PADOVANI et al., 2014; YOSETAKE et al., 2018), estratégias de organização do tempo (BASSO et al., 2013; MATTA; LEBRÃO; HELENO, 2017; OLIVEIRA et al., 2016) e ampliação de atividades de lazer e de convívio familiar e social (MATTA; LEBRÃO; HELENO, 2017; PADOVANI et al., 2014; YOSETAKE et al., 2018). Ainda, para combater a permanência prolongada (demorar mais tempo que o previsto para a conclusão dos cursos), Pereira et. al. (2015), enfatizam a construção de ações institucionais para a melhoria de desempenho acadêmico, como programas de suporte acadêmico (como tutorias e monitorias), estímulo à realização de estágio e aproximação da universidade à sociedade. Nesses estudos, restam como importantes o desempenho, a produtividade, a adaptação, a organização, sendo os estudantes os únicos responsáveis por seus sucessos ou fracassos; a instituição é, por conseguinte, somente considerada em relação às formas de apoio aos processos adaptativos.

A importância desses estudos reside em, de alguma forma, dar visibilidade a uma questão importante: os problemas enfrentados pelos estudantes universitários. Porém, também é preciso reconhecer que não avançam quanto a discussões necessárias sobre a produção da vida estudantil nas universidades e seus efeitos cotidianos, que se expressam em diversas formas de sofrimento abarcadas num conjunto denominado saúde mental. Por meio das análises que apresentam, como consequência, esses estudos mantém a velha lógica da produção do fracasso escolar e da individualização de sua responsabilidade à/ao próprio estudante (PATTO, 1999). Vejamos como os tempos e espaços nas universidades conformam a vida estudantil

\section{Produção dos Espaçotempos}

Ao tratar de condições que afetam a saúde mental e geram sofrimento às/aos estudantes nas universidades, o tempo emerge nos estudos citados como pouco explorado. Tempo, porém, forma um par dialético com o espaço, sendo mutuamente constitutivos e indissociáveis: são espaçotempos, transformações no espaço que se dão também no tempo, e vice-versa. No espaço, sempre "atual, sincrônico e dado como um todo" (LEFEBVRE, 2013, 
p. 164), residem acumulados de tempos, "o histórico, o diacrônico, o passado gerador deixa suas inscrições incessantes sobre o espaço" (LEFEBVRE, 2013, p. 164). De modo sincrônico, no espaço se pode ler a história das experiências humanas, configuração construída historicamente (CARERI, 2013).

O processo histórico de constituição das instituições educacionais ocorre conjuntamente com processos que organizam a vida em sociedade a partir da Modernidade. Nesse período, a organização do espaço esteve aliada à, e favoreceu a consolidação e avanços do sistema econômico capitalista, direcionada à produção e circulação de bens e de pessoas (BENJAMIN, 2015; LEFEBVRE, 2013; SANTOS, 2014). O espaço passa a ser racionalizado e linearizado para facilitar a circulação e o controle (predição das possibilidades de ocupação/utilização do espaço). Esse mesmo processo produziu, concomitantemente, as possibilidades de sentir, experienciar e compreender o que seja o tempo e suas relações (ELIAS, 1998; LEFEBVRE, 2013; SANTOS, 2014). Condicionado pelos relógios de movimento contínuo (aparelhos-símbolo da modernidade), o que compreendemos por tempo passa a ser organizado e produzido de modo a ser vivenciado e sentido por todas/os de modo homogêneo com o "estabelecimento progressivo de uma grade bem integrada de reguladores temporais (ELIAS, 1998, p. 36), criando-se a sensação de sincronicidade de processos, ações que ocorrem concomitantemente. Como efeito, buscam produzir espaçotempos homogêneos e experienciados por todas/os da mesma forma, velando usos e ocupações não previstas (CARERI, 2013; CERTEAU, 2014), tempos lentos que permitam ver restos e sobras desse processo (BENJAMIN, 2015; SANTOS, 2014).

Essa organização também se reflete no universo do trabalho, condicionando as formas e possibilidades em que ele se dá, constituindo não apenas possibilidades de sua realização, mas também das formas de vida na sociedade. A circulação de pessoas e produtos precisa ser ágil, em pouco tempo, em curto espaço. Produz-se, assim, uma série de condições e possibilidades, a materialidade objetiva em meio à qual se dão os processos de produção de subjetividades, de sensibilidades, dizibilidades e pensabilidades.

Esses mesmos processos também podem ser reconhecidos na produção das instituições de educação a partir da Modernidade (ESCOLANO, 2001; FRAGO, 2001; THIESEN, 2011). O que ocorre também com as instituições de ensino superior, que tem sido cada vez mais marcadas por aspectos de políticas econômicas (CHAUÍ, 2001, 2003, 2016; COSTA; GOULART, 2018; MANCEBO; SILVA JÚNIOR; SCHUGURENSKY, 2016; SANTOS, 2001, 2010; SIGAHI; SALTORATO, 2018), produzindo-se os espaçotempos em que a vida estudantil se dá (MACHADO; ZANELLA, 2018). Os espaçotempos onde a escolarização acontece não são, portanto, apenas lugares e tempos em que a transmissão de conhecimentos historicamente produzidos pela humanidade ocorre. Nas estruturas e formas de funcionamento das instituições de ensino residem vozes e valores sociais que dizem dos processos de formação e, consequentemente, dos processos de produção de subjetividades. 
Na história da instituição escolar, cada diferente concepção dos processos de ensinoaprendizagem define formas espaçotemporais em que os mesmos ocorrem: lugar de carteiras e demais mobiliários; divisão espacial por sexos; locais destinados a professoras/es, estudantes e funcionários/as; momentos de estudo, de recreação ou de atividades físicas; controle dos corpos e da disciplina; marcação do tempo com campainhas e sinais; distribuição de conteúdos conforme suas complexidades; serialização de turmas; duração das aulas; etc. (ARROYO, 2012; THIESEN, 2011). A partir do século XIX, com a consolidação das instituições educacionais coletivas, são adotados métodos de ensino simultâneos (atividades iguais a serem desenvolvidas por um coletivo), os quais estão atrelados à concepção de aluno médio, "representado pela escola como subordinado, disciplinado, atento, obediente, rápido, sempre ocupado, com resposta imediata e ajustado ao meio escolar, tendo uma relação produtiva e rigorosa com o tempo" (PINHO; SOUZA, 2015, p. 668). O aluno médio, portanto, condensa a idealização de que todas/os estabelecem com o tempo a mesma relação, não permitindo/possibilitando maleabilidade para formas diferentes de vivência/experiências com o tempo e de processos de aprendizagem. Ao se instituir o aluno médio, criam-se também categorias, acima e abaixo, as quais compreendem aquelas/es que não atendem aos requisitos médios. Respondendo a essas concepções, resultam princípios homogeneizadores que passam a organizar as instituições escolares: o tempo, o espaço, os conteúdos e sua ordenação, a serialização, etc. (MARQUES; OLIVEIRA; MONTEIRO, 2015; PINHO; SOUZA, 2015, 2017; THIESEN, 2011). A organização do processo ensino-aprendizagem é feita de modo semelhante à organização do mundo do trabalho, com ordenamento de jornadas e ritmos, hábitos de trabalho em contraposição à recreação ou lazer, e a valorização da produtividade (ARROYO, 2012). Nesse cenário, as práticas de ensino mais efetivas são aquelas que mais rapidamente submetem estudantes à sua lógica e deles obtém a melhor produtividade.

\section{Sofrimento, Exclusão e a Base Emotivo-volitiva das Ações}

Para compreender o humano em sua dimensão coletiva e singular é necessário abarcar suas condições materiais de existência, suas relações, os sentidos que envolvem suas ações; é preciso, segundo Sawaia (2006), lançar luz sobre a base emotivo-volitiva que motiva as ações humanas. Importa, pois, olhar o sujeito como centro, no qual suas experiências, possibilidades e condições de sensibilidade, dizibilidade e pensabilidade se objetivam como emoção, (des)motivação, necessidade, vontade. Focando a objetivação das formas de exclusão vivenciadas socialmente, Sawaia (2006) conceitua o sofrimento ético-politico como categoria para análise da "vivência cotidiana das questões sociais dominantes em cada época histórica, especialmente a dor que surge da situação social de ser tratado como inferior, subalterno, sem valor, apêndice inútil da sociedade” (p. 104).

Exclusão é analisada a partir da expressão dialética inclusão/exclusão, de modo que ambas formam um par indissociável, que se constitui em relação. Na dinâmica da vida, garantem a manutenção da ordem social via reconstituição incessante "de formas de desigualdade, como o processo de mercantilização das coisas" e das pessoas (SAWAIA, 
2006, p. 108). A partir dessa concepção, o sofrimento ético-político traduz-se na possibilidade de "analisar as formas sutis de espoliação humana por trás da aparência da integração social e, portanto, entender a exclusão e a inclusão como duas faces modernas de velhos e dramáticos problemas" (SAWAIA, 2006, p. 106).

No mesmo sentido, podemos depreender da filosofia da Linguagem do Círculo de Bakhtin contribuições para refletir sobre esse aspecto. $\mathrm{O}$ dialogismo, princípio filosófico da/nas obras do Círculo, que expressa o tenso e infinito diálogo entre vozes sociais (complexos semântico-axiológicos com os quais os grupos humanos dizem e constroem o mundo) (BAKHTIN, 2016, 2017, 2018; VOLÓCHINOV, 2017), assim como a teoria do signo linguístico (todo signo é ideológico ${ }^{4}$, não há signo ou enunciado que não expresse valores produzidos social e historicamente) (VOLÓCHINOV, 2017), congregam-se na filosofia do ato responsável. Para Bakhtin e o Círculo, todo ato é responsável e caracteriza-se como evento situado no mundo concreto das relações humanas, condição também da produção de sentidos no campo da linguagem (BAKHTIN, 2016; VOLÓCHINOV, 2017; VOLOCHÍNOV, 2013; MACHADO; ZANELLA, 2019). No universo ideológico e dialógico da linguagem, todo ato é sempre responsivo (por responder a atos/enunciados anteriores, numa teia dialógica), e responsável (em cada ato o sujeito assume a realização de uma decisão, um posicionamento num universo valorado e de tensões). O caráter responsável do ato, pois, não tem a ver com racionalidade, mas sim com a assumpção de posicionamento nas teias discursivas das vozes sociais, tendo centralidade o caráter emotivo-volitivo da ação, "momento imprescindível do ato" (BAKHTIN, 2010, p. 86). O tom emotivo-volitivo é o que "orienta no existir singular, que orienta e afirma realmente o conteúdo-sentido" (BAKHTIN, 2010 , p. 87). Inserido e respondendo na e às teias dialógicas, às tensões entre as vozes sociais (que também o constituem), o caráter volitivo da ação, conjuntamente com as condições materiais em que emerge no existir-evento, configuram sua condição singular.

Todo ato, pois, é singular e irrepetível posto que carrega, em sua composição, o caráter valorativo (ideológico), responsivo (dialógico), responsável (posicionamento nas teias dialógicas e orientado pelo tom emotivo-volitivo), as condições de possibilidades (contexto) no qual emerge. $\mathrm{O}$ ato, ao expressar um conjunto de valores construído social e historicamente, carrega em si também marcas do próprio sujeito, das condições e interesses que compõem o tom emotivo-volitivo na totalidade de sua arquitetônica. Nesse sentido, ao aproximarmos as conceituações do Círculo de Bakhtin às de Sawaia (2006), compreendemos que importa ao campo da Psicologia a dimensão discursiva e dialógica da linguagem, a qual possibilita compreender, a partir das condições emotivo-volitivas do sujeito, "os ingredientes psicossociais que sustentam os discursos dos excluídos no plano intra e intersubjetivo e o que custa a exclusão a longo prazo em termos de sofrimento" (SAWAIA, 2006, p. 113). Interessa, por conseguinte, a produção social do sofrimento ético-político considerando as tensões que o instituem e o modo como cada pessoa a elas responde.

\footnotetext{
${ }^{4}$ Ideológico, nesse contexto, refere-se à uma dimensão valorativa produzida de forma coletiva, num determinado tempo e espaço. Essa compreensão de que sejam dois universos coincidentes rompe com compreensões da linguagem humana como processo de comunicação que se dá entre emissor e receptor, no qual a linguagem é apenas um meio a ser codificado e decodificado entre ambos (FARACO, 2003; VOLÓCHINOV, 2017)
} 


\section{Da Realização do Estudo}

Com base na Filosofia da Linguagem do Círculo de Bakhtin (BAKHTIN, 2010, 2011, 2016, 2017; FREITAS, 2009; SOUZA; ALBUQUERQUE, 2012; VOLOCHÍNOV, 2013; 2017; MACHADO; ZANELLA, 2019), realizamos uma pesquisa ${ }^{5}$ de caráter interventivo (BRITO; ZANELLA, 2017; FREITAS, 2010), trabalhando com Oficinas (BRITO;ZANELLA, 2017; SPINK; MENEGON; MEDRADO, 2014). Desenvolvemos Oficinas de Fotografia mobile em uma universidade pública brasileira, as quais foram ofertadas como atividade de extensão a dois grupos de oito estudantes. Participaram 16 estudantes, divididos em dois grupos (essa quantidade foi definida de forma a buscar dar mais possibilidade de diálogo entre as/os participantes, pois em grupos maiores alguns poderiam se sentir inibidas/os), com idades entre 18 e 30 anos, sendo 12 mulheres, de diferentes cursos de graduação (Arquitetura e Urbanismo, Terapia Ocupacional, Ciências Biológicas, Expressão Gráfica, Jornalismo, Pedagogia e Direito). Elas/eles estão identificadas/os neste texto com seus nomes reais, conforme decisão em Termo de Consentimento Livre e Esclarecido (TCLE).

As Oficinas tiveram duração de oito semanas, com encontros semanais de duas horas cada, aproximadamente. Todos os encontros foram gravados em áudio e posteriormente transcritos. Realizamos as seguintes atividades: nas duas primeiras semanas, em sala, com base em fotografias, vídeos e mapas, discutimos o cotidiano na cidade e na universidade; o que é ou não visível nos espaços pelos quais se transita; a produção do olhar; a história da fotografia e a fotografia urbana; fotografia como produção de um sujeito e como recorte da realidade; questões técnicas e de composição; e a fotografia com o celular. Na terceira semana realizamos uma caminhada estética (CARERI, 2013) por espaços da cidade e da universidade. A quarta semana foi dedicada à produção de fotografias: solicitamos às/aos estudantes que produzissem fotografias a partir da seguinte questão: "o que você vê ou não em seu cotidiano na UniverS/Cidade?". Na quinta semana expusemos as fotografias ao grupo e discutimos e coletivamente cada uma delas. Na sexta semana, trabalhamos com a organização da exposição, com a escolha das fotografias e sua ordenação, discutindo sentidos que poderiam provocar. Na sétima semana foram montadas as exposições em dois espaços da universidade - uma exposição para cada grupo, as quais foram permutadas entre si após a quarta semana; permanecendo, portanto, as exposições abertas à visitação durante nove semanas $^{6}$. De 167 fotografias produzidas nas Oficinas, 120 (60 de cada grupo) foram selecionadas pelos/as estudantes para compor exposições. Na oitava e última semana das oficinas, realizamos uma discussão sobre as experiências em participar das Oficinas e quanto à produção de imagens e sobre a vida acadêmica.

\footnotetext{
${ }^{5}$ Projeto de pesquisa aprovado por Comitê de Ética em Pesquisa com Seres Humanos, conforme Certificado de Apresentação para Apreciação Ética n. ${ }^{\circ}$ : 59949416.9.0000.0121. e. Parecer de aprovação n. ${ }^{\circ}$ 1.767.876.

${ }^{6}$ Posteriormente foram transformadas em exposições virtuais permanentes - Página no Facebook: https://www.facebook.com/Oficinas-de-Fotografia-Mobile-UFPR-691044781079959/

Grupo 1: https://www.flickr.com/photos/149363309@N04/sets/72157682018495062/

Grupo 2: https://www.flickr.com/photos/149363309@N04/sets/72157681856242262/. \begin{tabular}{l|l|l|l|l}
\hline C) Rev. Inter. Educ. Sup. & Campinas, SP & v.7 & $1-22$ & e021034
\end{tabular} 2021
} 
O trabalho com fotografia junto aos/às estudantes foi realizado a partir da compreensão da mesma como linguagem, tomando-a principalmente a partir de suas dimensões discursiva e dialógica (ROUILLÉ, 2009; ZANELLA, 2011). A fotografia-imagem foi assumida como enunciado, uma "unidade real da comunicação discursiva" (BAKHTIN, 2016, p. 22) constituído nas teias discursivas, sendo uma resposta, produzida por alguém que, no ato ético e estético de sua produção, situado no mundo frente à e a partir de conjuntos de valores (ZANELLA, 2011, 2016). Interessa-nos no trabalho com a fotografia a forma como aquele/a que a produz grafa seu olhar ao/sobre o mundo, de que forma ele/a o compreende, o arranja, o produz, o enuncia e como se insere nas teias dialógicas (KOSSOY, 2012; ROUILLÉ, 2009; ZANELLA, 2011).

Com base nessa compreensão, o trabalho com as fotografias foi realizado articulandoas com, e problematizando, os olhares e visibilidades/invisibilidades cotidianas na UniverS/Cidade; questões técnicas da fotografia compuseram o trabalho como um elemento para a construção das mesmas, não tendo lugar central nas discussões. Assim, o que as/os estudantes produziram (imagens e falas) foram considerados, nas análises, como respostas: ao contexto das oficinas; às problemáticas levantadas pelo pesquisador (a forma de organização e lógicas que constituem a universidade e a cidade, rotinas universitárias, etc.); às obras de fotógrafos e outros artistas que expusemos como disparadores das discussões; às formas histórica e socialmente produzidas de se constituir imagens; às hierarquias e imagens que estão presentes na relação entre o pesquisador e participantes da pesquisa; às condições que a universidade lhes apresenta.

As análises que construímos pautaram-se na compreensão de que o/a pesquisador/a compõe as situações de interlocução, não sendo neutro e/ou isento, mas sim sujeito ativo na produção de sentidos e nos diálogos entre as vozes sociais analisadas. Buscamos, nos enunciados verbais e imagéticos analisados, ver/ouvir as vozes sociais que ali se fazem visíveis e ecoam, bem como os efeitos que produzem (marcadas por expressões de sofrimento) no cotidiano da vida acadêmica.

\section{(In)Visibilidade e (In)dizibilidade às/nas Tramas Discursivas na/da Universidade}

No terceiro encontro das Oficinas, com projetor multimídia, exibimos as imagens produzidas pelas/os estudantes, o que foi acompanhado de leituras e interpretações realizadas e discutidas pelo grupo. As discussões foram instigadas pelo pesquisador que lançava questões tanto às/aos autoras/es das imagens, para que pudessem falar um pouco mais sobre elas, sobre os locais retratados, o que os motivara à produção (um pouco da história das imagens), quanto às/aos demais estudantes do grupo.

No Grupo 1 emergiram discussões a respeito da imagem produzida por Deivisson ${ }^{7}$ (Figura 1), estudante de Terapia Ocupacional.

${ }^{7}$ Os nomes das/os estudantes são reais, conforme opção que fizeram na assinatura de Termo de Consentimento Livre e Esclarecido. 
Figura 1. Fotografia produzida por Deivisson dos Santos Soares

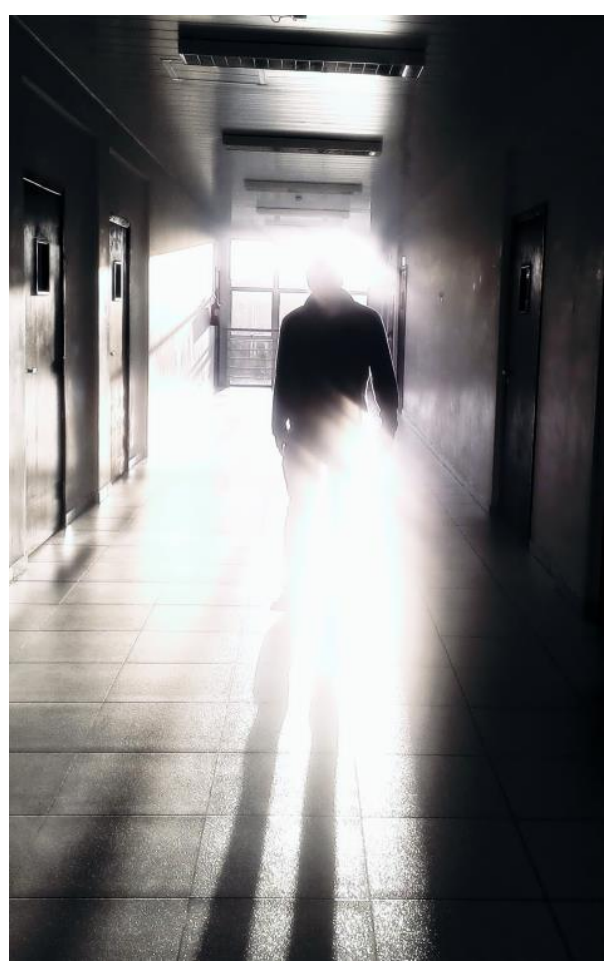

Fonte: Deivisson dos Santos Soares - fotografia produzida no âmbito das Oficinas de Fotografia Mobile

A imagem produzida por Deivisson chamou a atenção das/os colegas à questão dos agravantes de saúde mental das/os estudantes em decorrência das demandas acadêmicas:

Juliana (estudante de Jornalismo): Nossa, ficou bem macabra essa! Bem tipo capa de filme de terror.

Deivisson: (risos) Então, na verdade eu achei bem interessante a luz, que estava bem... que estava incidindo bem no corredor, assim. Daí meu amigo estava lá e eu pedi pra ele ficar ali. Porque eu tive uma... assim, eu tive duas palestras que tratava, falava da ansiedade e da depressão em universitários. E é bem essa questão, assim, de como a carga horária, de como a intensidade da vida universitária é... prejudica e... prejudica a questão da saúde mental mesmo, porque tem pessoas que não conseguem lidar, muitas vezes com as questões, com as demandas que a universidade tem, né? Que é rotina.

Juliana: Não tem saúde mental na universidade.

Pesquisador $^{8}: \mathrm{E}$ a tua ideia nessa foto era retratar um pouco disso?

Deivisson: É, e até mesmo a contradição que tem nos cursos de saúde. Muitas vezes... pelo menos no meu curso tem muito essa coisa de considerar o próximo e de entender o outro, só que muitas vezes a carga horária, a questão da instituição mesmo, não permite que... tipo, a gente só tem que se adequar à rotina e cumprir o que tem pra cumprir. Não...

Pesquisador: Então você tem que dar conta da saúde do outro só?

Deivisson: É. A nossa saúde não é considerada (ri).

Juliana: Pesado isso que você falou.

Gustavo (estudante de Expressão Gráfica): ri.

Pesquisador: Você se identifica com isso? (pergunta à Juliana)

Juliana: Bastante.

Pesquisador: Alguém mais?

8 "Pesquisador" refere-se ao primeiro autor deste trabalho.

\begin{tabular}{l|l|l|l|l|l}
\hline (C) Rev. Inter. Educ. Sup. & Campinas, SP & v.7 & $1-22$ & e021034 & 2021 \\
\hline
\end{tabular}


Gustavo: Eu não me identifico mais, né, porque... Mas eu já passei por semanas sem sono também.

Juliana: Nossa, semana passada eu estava fazendo as contas, eu fiquei 44 horas sem dormir, fazendo trabalhos.

Gustavo: É, então... Mas eu, uma hora vi que era isso que estava acontecendo e falei "É, não... não vou dar prioridade pra ficar mal". E tanto é que eu abandonei algumas matérias e atrasei o curso, assim, mas...

Juliana: Mas eu não tenho mais essa possibilidade. Eu estou com um semestre atrasado já e o meu curso mudou o currículo agora. Então eu tenho que me adequar, sabe? Porque as matérias que eu estou tendo não vão mais ser oferecidas.

Gustavo: Ou corre, ou corre.

A imagem "macabra", de "capa de filme de terror", como afirma Juliana, foi composta pelo estudante com a intenção, segundo ele, de referir-se a aspectos de saúde mental das/os estudantes na universidade frente à carga horária e à intensidade da vida acadêmica.

No mesmo sentido da intensidade da vida na universidade, no encontro final discutíamos sobre o processo das Oficinas, sobre as experiências e sentidos atribuídos pelas/os estudantes. Fazendo parte do processo das Oficinas, também questionávamos como era, para elas/es, ver seus trabalhos expostos na universidade, se colegas e amigos tinham visto, que comentários ouviram, etc. Frente a essa questão, Juliana respondeu não ter tido tempo de ver as exposições devido à correria e o volume de atividades a serem cumpridas. Com base nisso, o pesquisador questionou às/aos estudantes sobre suas percepções referentes ao tempo na vida universitária:

Pesquisador: Tem muita correria, então, na universidade? O que vocês acham?

Leomara (estudante de Ciências Biológicas): Não sei, eu acho que... pelo menos no meu caso, assim. Eu me cobro de me organizar mais. Porque um pouco dessa correria é porque eu vou deixando as coisas, assim... Daí... Mas, em geral tem sim. As vezes atrapalha um pouco a vida...

Gustavo: Social...

Leomara: É. Não, não existe (ri). Dentro da universidade, assim, que você tem vida social. Fora é bem raro. Complicado. Não sei se faz parte...

Daniela: Na minha sala tem um monte de gente com ansiedade, com crises de ansiedade, pessoas tomando remédio porque... Tá uma correria enorme, eu to no meu quarto ano, então tem TCC (Trabalho de Conclusão de Curso) e mais estágio e as vezes o estágio também a gente não está preparado pra ver o que a gente vê, assim. Igual no semestre passado eu fiz... era com criança, com neuropediatria. Daí a gente não vai... vai sem preparação nenhuma. A gente vai lá, chega uma criança com uma síndrome rara e tu... e a gente não sabe como lidar. Tá lidando com pessoas, ali o tempo todo, é difícil. E a cobrança do TCC, que tem prazo e... Porque o TCC é uma disciplina...

Leomara: Tá um caos..

Juliana: Eu e meus amigos, tem vezes que a gente fala que a faculdade é uma falta do que fazer, porque... tá todo mundo assim... surtando o tempo inteiro. Isso que ela falou, de que tá todo mundo com crise de ansiedade, tomando remédio... Grande parte da minha turma também tá nessa. Não é exclusividade.

Daniela: A gente cuida dos outros mas não cuida da gente (ri). (inaudível) fala que o pessoal que é profissional da saúde é o que menos cuida da saúde. Cuida dos outros e não cuida de si.

Gustavo: É, prefiro mexer com máquinas... (risos). Eu, dentro da vida acadêmica, assim, tive umas correrias, mas de leve. Eu nunca cheguei a me desesperar, mas é porque eu nunca dei tanta prioridade assim pra vida acadêmica. Eu sempre priorizei projetos fora e a academia ficava em segundo plano. Tanto é que atrasei o meu curso. Mas ainda assim você consegue sentir um pouco da correria. Você vê um

v.7

$1-22$

$\mathrm{e} 021034$
2021 
amigo que se desespera porque está perdendo o prazo disso, prazo daquilo. E tem toda a cobrança externa também, da família, ou de emprego... acaba não sendo só da tua cobrança, tem muita gente assim. Mas eu tenho passado uma graduação bem tranquila (ri).

Ao responderem à pergunta do pesquisador, as/os estudantes falaram sobre as condições nas quais estão inseridas/os e de que forma elas produzem suas sensibilidades, dizibilidades e pensabilidades. Na imagem produzida por Deivisson é possível ler e ver/ouvir também respostas a outras vozes sociais, algumas enumeradas por ele: a de uma palestrante que falou aos estudantes sobre ansiedade e depressão; a de estudantes do seu curso, colegas talvez, ou de cursos da área de saúde, que apontam uma contradição nos cursos de saúde, posto que importa a saúde do outro, e não do estudante; vozes de estudantes de outros cursos, que ressoam nas falas de Juliana e de Gustavo, ao enunciarem efeitos das condições de vida nas quais estão inseridos; vozes que dizem da organização espaçotemporal na educação, constituindo ritmos e intensidades a serem seguidas pelas/os estudantes; assim como vozes institucionais que, por vezes, ao evidenciarem os louros da universidade, silenciam efeitos outros, como o sofrimento que resta como um de seus produtos.

Juliana, que diz se identificar com o apresentado por Deivisson, também diz que o tempo é aspecto importante a ser considerado quando se fala em saúde mental. Relata ter ficado mais de 40 horas sem dormir para conseguir finalizar trabalhos acadêmicos. Porém, nessa discussão do terceiro encontro, Gustavo, do mesmo modo que o faz na discussão do último, apresenta a fórmula que adotou para não passar pelo que as/os demais se referiram: cancelar disciplinas, atrasar o tempo para conclusão do curso, não dar prioridade à vida acadêmica. Essa ação, porém, parece ter um preço, a não conclusão do curso no tempo previsto, ao qual Gustavo esteve disposto a pagar. Para Juliana, porém, por mudanças de currículo, esse preço não é possível: “eu tenho que me enquadrar, sabe?".

As vozes que sustentam lógicas quanto à produtividade (formar profissionais em determinado tempo, números relacionados aos custos da formação na instituição) e à necessidade de um tempo a ser cumprido e vivenciado de certo modo, parecem tecer condições nas quais, por vezes, algumas estratégias de enfrentamento não são possíveis. Restam, frente a elas, adequações: "ou corre, ou corre", conclui Gustavo sobre a situação de Juliana. Nesse sentido, frente à possibilidade de exclusão dos incluídos no ensino superior público federal, as tramas da organização do tempo, da pretensa sincronicidade de processos a serem vivenciados e cumpridos por todos, da suposta homogeneidade de estudantes que pauta a organização acadêmica e desconsidera diversidades, produz-se a individualização de problemáticas. As dificuldades enfrentadas pelos/as estudantes são imputadas a eles/as mesmos/as, que para enfrenta-las recorrem a estratégias de organização do tempo. Essa trama resulta na produção de subjetividades mais adaptáveis e disponíveis à intensificação de condições de trabalho precarizadas, conforme analisam Mancebo et al. (2016) e Sigahi e Saltorato (2018). É possível ouvir na fala de Leomara ("Eu me cobro de me organizar mais, assim. Porque um pouco dessa correria é porque eu vou deixando as coisas”) vozes que, ao instituírem as condições e possibilidades da vida acadêmica, ainda incutem a responsabilidade pelo fracasso às/aos estudantes que não conseguem, de alguma forma, dar

\begin{tabular}{|l|l|l|l|l|l|} 
(C) Rev. Inter. Educ. Sup. & Campinas, SP & v.7 & $1-22$ & e021034 & 2021 \\
\hline
\end{tabular}


conta das atividades. A instituição universitária, ao fazer prevalecer nas políticas que regem a organização da vida acadêmica vozes sociais que preconizam produtividade, flexibilidade, individualização, aceleração e homogeinização de espaçostempos, institui mecanismos que produzem sofrimento, efeito do sentimento de não adequação, incapacidade, insuficiência. No mesmo processo, produz-se também o silenciamento desse sentimento de não adequação que, se visibilizado ou audível, é significado por essas mesmas vozes como motivos que justificam a exclusão.

Nessa complexa trama a vida social, o fora da instituição, "atrapalha" ou "não existe". Medicação, crises, cobranças e "surtos" podem ser lidas como respostas das/os estudantes frente ao contexto no qual estão inseridos e ao qual foram convidados a refletir com o trabalho de produção fotográfica e de leitura das imagens produzidas.

No Grupo 2, também emergiram discussões que trouxeram o sofrimento como indicador de importantes questões relacionadas às condições da vida acadêmica. No encontro em que apresentamos as fotografias ao grupo, o pesquisador instiga Thuany (estudante de Arquitetura e Urbanismo) quanto ao processo de criação e composição fotográfica, assim como dos elementos que escolhera para compor uma de suas imagens (Figura 2):

Figura 2. Fotografia produzida por Thuany Aline Santos

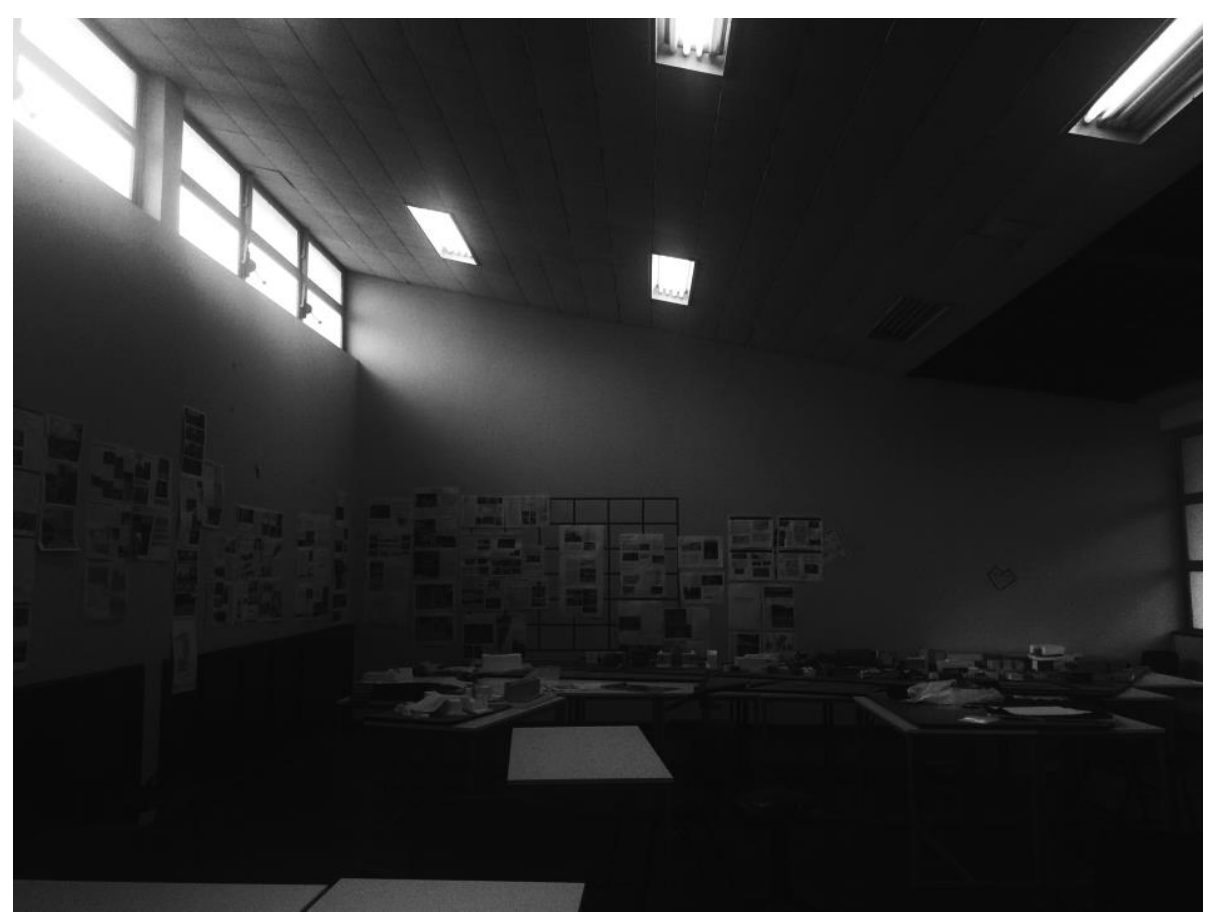

Fonte: Thuany Aline Santos - fotografia produzida no âmbito das Oficinas de Fotografia Mobile

Pesquisador: Por que o preto e branco aqui nessa sala?

Thuany: Eu tenho uma foto dela, dessa mesma sala, que eu tirei no começo do ano, quando estava tudo organizado, assim, perfeita simetria; todas as cadeiras eram alinhadinhas... E essa foto eu tinha deixado em preto e branco... eu acho que é porque essa sala, pra mim, ela foi muito traumática, assim. Daí eu olho... agora a gente está tendo aulas de novo nessa sala aí e eu detesto ter aula nela. Porque eu lembro da desgraça que foi o ano passado. Não sei, eu não consigo associar com

\begin{tabular}{l|l} 
v.7 & $1-22$
\end{tabular}

e021034


cores e com vida, e com coisas legais que aconteceram nessa sala. Então, pra mim tem que ser preto e branco. Acho que é isso.

Pesquisador: Mas aconteceu algo de ruim nessa sala?

Thuany: Não, é porque o ano passava foi um ano de crise, eu quase desisti da

faculdade... e essa carga horária exagerada, então... Acho que foi um pouco disso.

Ao questionar o porquê de algumas fotos terem sido produzidas em preto e branco, o pesquisador busca compreender motivações que levaram a estudante a compor a fotografia daquela forma. Nesse sentido, compreendemos que importa não apenas aquilo que na fotografia aparece, mas também a relação forma-conteúdo com que é produzida e a intencionalidade de quem as produziu. O preto e branco, comumente associado a sentimentos e sensações de tristeza, vazio, etc., é utilizado pela estudante com essa mesma intenção.

Quantos estudantes não chegam a situações limite como a de Thuany, de quase desistir do curso ou de fazê-lo? Em preto e branco, sala bagunçada, carteiras desalinhadas, janelas de onde as luzes jorram, banhando paredes e trabalhos expostos - há mais do que referentes, há experiências e o olhar da estudante para a sala visibilizada na imagem. A sala à qual Thuany não consegue "associar com cores e com vida, e com coisas legais", resta como resultado de um processo, "traumático", que faz lembrar a "desgraça que foi o ano passado", marcado por "exagero" de carga horária.

No mesmo encontro, enquanto visualizávamos as imagens produzidas por Jackson (estudante de Arquitetura e Urbanismo), ele comenta sobre uma delas (Figura 3):

Figura 3. Fotografia produzida por Jackson Reis Rispoli de Oliveira

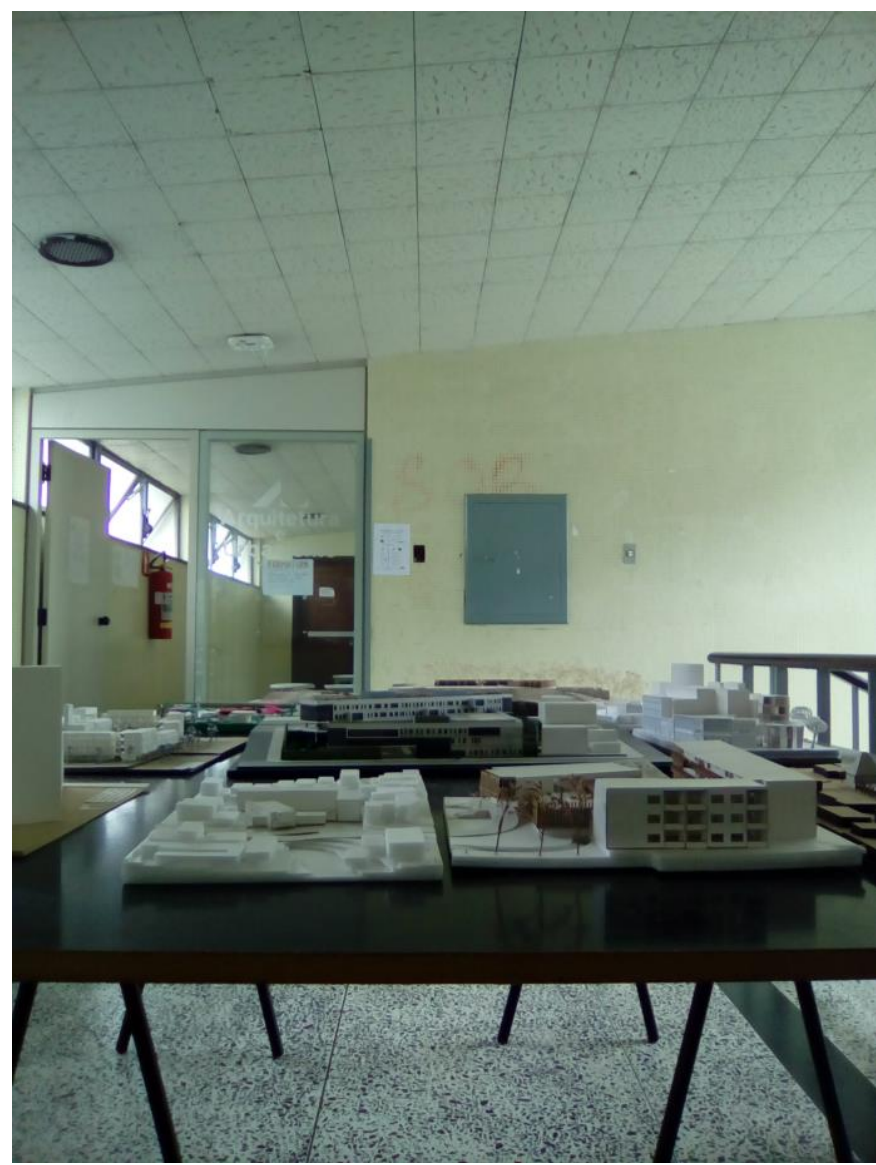

Fonte: Jackson Reis Rispoli de Oliveira - fotografia produzida no âmbito das Oficinas de Fotografia Mobile 
Jackson: A sexta foto é ali na frente do Departamento de Arquitetura. Aí tem essas maquetinhas ali. Aí eu pensei: "nossa, as pessoas que passam ali e veem essas maquetinhas, elas: 'nossa, que bonitinho!'” (ri). Elas não sabem o sangue e o suor... (risos) dessas maquetinhas. Então eu achei interessante também fotografar.

Pesquisador: Quem é da arquitetura? (estudantes se identificam - neste grupo, eram cinco, de oito participantes).

Jackson: E essas aí (maquetes que são retratadas na imagem) são do TFG (Trabalho Final de Graduação), mais elaboradinhas, assim.

Carla (estudante de Arquitetura e Urbanismo): Geralmente elas não ficam tão bonitas (risos).

Jackson: Não... Mas o esforço é o mesmo.

No contexto das Oficinas em que produziram suas fotografias, as/os estudantes foram convidadas/os a refletir sobre seus olhares, sobre o que veem ou não em seus cotidianos na UniverS/Cidade. Ao falarem sobre as imagens e o processo de sua produção, os/as autores/as nos possibilitam acessar algo que a princípio não nos é acessível. Ao fotografar maquetes em exposição nos corredores do departamento em que tem aulas, Jackson provoca o/a leitor/a a perscrutar o jogo de visibilidades e invisibilidades que caracterizam a imagem como produção discursiva, com as tensões que a conotam. O referente, as bonitas maquetes expostas, vela algo que a narrativa sobre o processo de produção e a intencionalidade do autor revelam ao leitor: o sangue e o suor despendidos na construção dos trabalhos expostos à comunidade acadêmica. O visível aos olhos guarda em si uma dimensão outra, não aparente. Assim como as maquetes, os resultados das universidades nos rankings das melhores instituições ou de avaliações do sistema de educação também se constituem via jogos de visibilidades e invisibilidades, com seus efeitos para a comunidade acadêmica.

As imagens e falas, os diálogos e as narrativas sobre o processo de produção das fotografias-enunciados proferidos pelos/as estudantes, caracterizam-se, no contexto das Oficinas, como respostas a um conjunto de vozes sociais que constituem a vida acadêmica. Assim, ao retomarmos as questões que enumeramos no início deste trabalho, enfatizamos a necessidade de se construir formas para que seja possível a escuta de outras vozes sociais eutras, para que possam ser proferidas pelas/os estudantes, que tornem audíveis e visíveis efeitos da configuração da vida estudantil nas universidades que tem sido invisibilizados e silenciados. Essas outras vozes, apresentadas aqui brevemente, nos remetem a questões que envolvem as formas pelas quais o tempo é experenciado pelos/as estudantes, assim como seu par dialético, o espaço. As instituições de ensino estão organizadas sob a égide de exigências de produtividade, pelos cálculos de custos e posições em rankings, e organizam a vida acadêmica via vozes que ocupam, nela, lugar de centralidade. Escutar as/os estudantes e ler as imagens que produziram permitem visibilizar e ouvir vozes outras, as quais denunciam formas sutis de exclusão em que o sofrimento resta como produto. 


\section{Considerações Finais}

Os enunciados de sofrimento das/os estudantes universitários/as que participaram das Oficinas emergiram como resposta ao convite para olharem os espaçotempos cotidianos. Ao direcionarem seus olhares aos modos como suas próprias vidas são organizadas na e pela UniverS/Cidade, passaram a visibilizar o que até então estava invisibilizado em suas rotinas, o quanto de "sangue e suor" há naquilo que cumprem todos os dias. Ao fazerem isso, denunciaram os efeitos perversos das lógicas que predominam nas instituições de educação superior, balizadas por vozes sociais que preconizam interesses mercadológicos.

Os enunciados que expressam sofrimento que emergiram nas Oficinas, seja nas imagens-enunciados, nas falas sobre o processo de produção das próprias fotografias ou nas discussões decorrentes do convite ao olhar o cotidiano de outra forma, denunciam, via tom emotivo-volitivo, as lógicas de organização social das instituições que, no mesmo processo em que produzem possibilidades de sensibilidades, dizibilidades e pensabilidades, culpabilizam individualmente aquelas/es que, de uma forma ou de outra, não se enquadram ou adequam, promovendo como efeito o sofrimento de que falam os/as estudantes.

Os enunciados que emergiram em resposta ao convite ao olhar e à produção de imagens, retratam, portanto, formas de exclusão que estão invisibilizadas e das quais pouco se tem falado nas instituições de ensino superior. Ao mesmo passo, evidenciam as vozes que tem centralidade e que constituem as formas de ser nesses espaçostempos e o modo como impactam na produção das condições da vida acadêmica. Trazem à tona aspectos e condições veladas que não são retratadas em rankings ou índices de qualidade da educação; tornaram visíveis e puderam dizer daquilo que não é possível ser dito dentro de lógicas que tem centralidade nas instituições de educação, ou seja, daquilo que resta como não aparente, sangue e suor que sustentam e condicionam estruturas, comportamentos, formas de agir, pensar e sentir. Nas Oficinas, pelo convite a olhar o cotidiano, foi possível construir práticas nas quais o que não é aparente pode não apenas ser revelado, mas dito e discutido.

A pesquisa realizada possibilitou também visibilizar a importância da constituição de espaços em que tensões constitutivas das lógicas que regem a vida acadêmica possam ser visibilizadas, que o sofrimento ou outros sentimentos possam ser ditos, pensados, compreendidos na complexa trama de vozes que os institui, condição para que possam ser reconsideradas algumas de suas dimensões. Nesse sentido, compreendemos que essa construção deva se dar não exclusivamente pela ampliação de serviços de atenção à saúde mental, ou com trabalhos voltados à organização do tempo e de estudos para que se consiga dar conta de um número cada vez maior de demanda. A disponibilização e ampliação do quadro de profissionais da psicologia nos espaços educacionais é importante, porém, a transformação do cenário visibilizado com a pesquisa requer a problematização dos valores que alicerçam e que estão presentes no variados espaços e tempos da universidade, assim como de outros níveis de ensino. Possibilitar que sejam ouvidas as vozes que falam desse sofrimento, bem como tensionados os enunciados que as reproduzem, é fundamental para essa transformação. 


\section{Referências}

ARROYO, Miguel González. Imagens quebradas: trajetórias e tempos de alunos e mestres. Petrópolis - RJ: Vozes, 2012.

BAKHTIN, Mikhail. Para uma filosofia do ato responsável. São Carlos: Pedro \& João Editores, 2010.

BAKHTIN, Mikhail. O autor e a personagem na atividade estética. In: BAKHTIN, Mikhail. Estética da Criação Verbal. 6.a ed. São Paulo: WMF Martins Fontes, 2011. p. 3-194.

BAKHTIN, Mikhail. Os gêneros do discurso. São Paulo: Editora 34, 2016.

BAKHTIN, Mikhail. Por uma metodologia das ciências humanas. In: BAKHTIN, Mikhail. Notas sobre literatura, cultura e ciências humanas. São Paulo: Editora 34, 2017. p. 57-79.

BAKHTIN, Mikhail. Estética da Criação Verbal. 6.a ed. São Paulo: WMF Martins Fontes, 2018.

BASSO, Claudia et. al. Organização de tempo e métodos de estudo: Oficinas com estudantes universitários. Revista Brasileira de Orientação Profissional, v. 14, n. 2, p. 277-288, 2013. Disponível em: http://pepsic.bvsalud.org/pdf/rbop/v14n2/12.pdf. Acesso em 25 ago. 2020.

BENJAMIN, Walter. Baudelaire e a modernidade. Belo Horizonte: Autêntica Editora, 2015.

Brito, Renan de Vita Alves; ZANELLA, Andréa Vieira. Formação ética, estética e política em oficinas com jovens: tensões, transgressões e inquietações na pesquisa-intervenção. Bakhtiniana: Revista de Estudos Do Discurso, 12(1), 42-64. 2017. Disponível em: https://www.scielo.br/pdf/bak/v12n1/2176-4573-bak-12-01-0042.pdf. Acesso em 25 ago. 2020.

CARERI, Francesco. Walkscapes: o caminhar como prática estética. São Paulo: Editora G. Gili, 2013.

CERTEAU, Michel de. A invenção do cotidiano: Artes do Fazer. Petrópolis: Vozes, 2014.

CHAUÍ, Marilena. Escritos sobre a universidade. São Paulo: Editora UNESP, 2001.

CHAUÍ, Marilena. A universidade pública sob nova perspectiva. Revista Brasileira de Educação, n. 24, p. 5-15, 2003. Disponível em:

https://www.scielo.br/pdf/rbedu/n24/n24a02.pdf. Acesso em 25 ago. 2020.

CHAUÍ, Marilena. Palestra de abertura. Contra a universidade operacional e a servidão voluntária. Salvador: UFBA, 14 jul. 2016. Disponível em:

http://www.congresso.ufba.br/?p=1658. Acesso em: 25 ago. 2020. 
COSTA, Camila Furlan da; GOULART, Sueli. Capitalismo acadêmico e reformas neoliberais no ensino superior brasileiro. Cad. EBAPE, v. 16, n. 3, p. 396-409, 2018. Disponível em: https://www.scielo.br/pdf/cebape/v16n3/1679-3951-cebape-16-03-396.pdf. Acesso em: 25 ago. 2020

ELIAS, Norbert. Sobre o Tempo. Rio de Janeiro: Jorge Zahar Ed., 1998.

ESCOLANO, Augustín. Arquitetura como programa: Espaço-escola e currículo. In: FRAGO, Antonio Viñao; ESCOLANO, Augustín (Org.). Currículo, espaço e subjetividade: a arquitetura como programa. Rio de Janeiro: DP\&A, 2001. p. 19-57.

ESPIRIDIÃO, Elizabeth et. al. A saúde mental do aluno de enfermagem: revisão integrativa da literatura. Rev. Eletrônica Saúde Mental Álcool Drog., v. 9, n. 3, p. 144-153, 2013. Disponível em: https://www.redalyc.org/articulo.oa?id=80331797008_2 . Acesso em: 25 ago. 2020.

FARACO, Carlos Alberto. Linguagem e Diálogo: as ideias linguísticas do círculo de Bakhtin. Curitiba: Criar Edições, 2003.

FRAGO, Antonio Viñao. Do espaço escolar e da escola como lugar: propostas e questões. In: FRAGO, Antonio Viñao; ESCOLANO, Augustín (Org.). Currículo, espaço e subjetividade: a arquitetura como programa. Rio de Janeiro: DP\&A, 2001. p. 59-140.

FREITAS, Maria Teresa de Assunção. A pesquisa de abordagem histórico-cultural: um espaço educativo de constituição de sujeitos. Teias, n. 10, p. 1-12, 2009. Disponível em: https://www.e-publicacoes.uerj.br/index.php/revistateias/article/view/24057. Acesso em: 25 ago. 2020.

FREITAS, Maria Teresa de Assunção. Discutindo sentidos da palavra intervenção na pesquisa de abordagem histórico-cultural. In: FREITAS, Maria Teresa de Assunção; RAMOS, Bruna Sola (Org.). Fazer pesquisa na abordagem histórico-cultural: metodologias em construção. Juiz de Fora: Ed. UFJF, 2010. p. 13-24.

GRANER, Karen Mendes; RAMOS-CERQUEIRA, Ana Teresa de Abreu. Revisão integrativa: sofrimento psíquico em estudantes universitários e fatores associados. Ciência \& Saúde Coletiva, v. 24, n. 4, 2017. Disponível em: https://www.scielo.br/pdf/csc/v24n4/14138123-csc-24-04-1327.pdf. Acesso em: 25 ago. 2020.

INEP, Instituto Nacional de Pesquisas Educacionais Anísio Teixeira. Resumo técnico. Censo da Educação Superior 2016. Brasília: INEP, 2018.

KOSSOY, Boris. Fotografia \& História. São Paulo: Ateliê Editorial, 2012.

LEFEBVRE, Henri. La Producción del espacio. Madrid: Capitán Swing Libros, 2013.

MACHADO, Jardel Pelissari; ZANELLA, Andréa Vieira. Entre cicatrizes e esqueletos: olhares trapeiros para tensões esquecidas na UniverS/Cidade. In: FONSECA, Tania Mara Galli; CAIMI, Claudia Luiza; COSTA, Luis Artur; SOUZA, Edson Luis André (Org.), Imagens do fora: um arquivo da loucura. Porto Alegre: Sulina. 2018. pp. 315-335. 
MACHADO, Jardel Pelissari; ZANELLA, Andréa Vieira. Bakhtin, ciências humanas e psicologia: diálogos sobre epistemologia e pesquisa. Psicologia \& Sociedade, v. 31.

Disponível em: https://doi.org/10.1590/1807-0310/2019v31166423. Acesso em 25 ago. 2020.

MANCEBO, Deise.; SILVA JÚNIOR, João dos Reis; SCHUGURENSKY, Daniel. A educação superior no Brasil diante da mundialização do capital. Educação em Revista, v. 32, n. 4, p. 205-225, 2016. Disponível em: https://www.scielo.br/pdf/edur/v32n4/1982-6621edur-32-04-00205.pdf. Acesso em: 25 ago. 2020.

MARQUES, Luciana Pacheco; OLIVEIRA, Cristiane Elvira de Assis; MONTEIRO, Sandrelena da Silva. Os usos dos tempos no cotidiano escolar. Revista Diálogo Educacional, v. 15, n. 608, p. 225, 2015. Disponível em:

https://periodicos.pucpr.br/index.php/dialogoeducacional/article/view/5116. Acesso em: 25 ago. 2020.

MATTA, Cristiane Maria Barra; LEBRÃO, Susana Marraccini Giampietri; HELENO, Maria Geralda Viana. Adaptação, rendimento, evasão e vivências acadêmicas no ensino superior: Revisão da literatura. Psicologia Escolar e Educacional, v. 21, n. 3, p. 583-591, 2017. Disponível em: https://www.scielo.br/pdf/pee/v21n3/2175-3539-pee-21-03-583.pdf. Acesso em: 25 ago. 2020.

OLIVEIRA, Clarissa Tochetto de; TEIXEIRA. Marco Antônio Pereira; CARLOTTO, Rodrigo Carvalho; DIAS, Ana Cristina Garcia. Oficinas de Gestão do Tempo com Estudantes Universitários. Psicologia: Ciência e Profissão, v. 36, n. 1, p. 224-233, 2016. Disponível em: https://www.scielo.br/pdf/pcp/v36n1/1982-3703-pcp-36-1-0224.pdf. Acesso em: 25 ago. 2020.

PADOVANI, Ricardo da Costa et. al. Alexsandro Firmino; LAMEU, Joelma do Nascimento. Vulnerabilidade e bem-estar psicológicos do estudante universitário. Revista Brasileira de Terapias Cognitivas, v. 10, n. 1, p. 2-10, 2014. Disponível em: http://www.rbtc.org.br/detalhe_artigo.asp?id=188. Acesso em: 25 ago. 2020.

PATTO, Maria Helena Souza. A produção do fracasso escolar: histórias de submissão e rebeldia. São Paulo: Casa do Psicólogo, 1999.

PEREIRA, Alexandre Severino et. al. Fatores relevantes no processo de permanência prolongada de discentes nos cursos de graduação presencial: um estudo na Universidade Federal do Espírito Santo. Ensaio: Avaliação e Políticas Públicas em Educação, v. 23, n. 89, p. 1015-1039, 2015. Disponível em: https://www.scielo.br/pdf/ensaio/v23n89/1809-4465ensaio-23-89-1015.pdf. Acesso em: 25 ago. 2020.

PINHO, Ana Sueli Teixeira; SOUZA, Elizeu Clementido de. O tempo escolar e o encontro com o outro: do ritmo. Educação e Pesquisa, v. 41, n. 3, p. 663-678, 2015. Disponível em: https://www.scielo.br/pdf/ep/v41n3/1517-9702-ep-41-3-0663.pdf. Acesso em 25 ago. 2020.

PINHO, Ana Sueli Teixeira; SOUZA, Elizeu Clementido de. Fios que Tecem o Tempo Escolar : do ritmo padrão à simultaneidade. Educação \& Realidade, v. 42, n. 3, p. $1183-$ 1204, 2017. Disponível em: https://www.scielo.br/pdf/edreal/v42n3/2175-6236-edreal60927.pdf. Acesso em 25 ago. 2020. 
ROUILLÉ, André. A fotografia: entre documento e arte contemporânea. São Paulo: Editora Senac São Paulo, 2009.

SANTOS, Boaventura de Souza. S. Pela mão de Alice: o social e o político na Pósmodernidade. São Paulo: Cortez, 2001.

SANTOS, Boaventura de Souza. A universidade no século XXI: para uma reforma democrática e emancipatória da universidade. 3. ed. São Paulo: Cortez, 2010.

SANTOS, Milton . A natureza do espaço: Técnica e Tempo, Razão e Emoção. 8.a ed. São Paulo: edusp, 2014.

SAWAIA, Bader Burihan. Sofrimento ético-político como categoria de análise da dialética exclusão/inclusão. In: SAWAIA, Bader Burihan. (Org.). As artimanhas da exclusão: análise psicossocial e ética da desigualdade social. Petrópolis - RJ: Vozes, 2006. p. 97-118.

SIGAHI, Tiago Fonseca Albuquerque Cavalcanti.; SALTORATO, Patrícia. A emergência da universidade operacional: redes, liquidez e capitalismo acadêmico. Educação \& Sociedade, v. 39, n. 144, p. 522-546, 2018. Disponível em: https://www.scielo.br/pdf/es/v39n144/16784626-es-es0101-73302018187694.pdf. Acesso em 25 ago. 2020.

SOUZA, Solange Jobim e; ALBUQUERQUE, Elaine Deccache Porto. A pesquisa em ciências humanas: uma leitura bakhtiniana. Bakhtiniana, v. 7, n. 2, p. 109-122, 2012. Disponível em: https://www.scielo.br/pdf/bak/v7n2/08.pdf. Acesso em 25 ago. 2020.

SPINK, Mary Jane.; MENEGON, Vera Mincoff; MEDRADO, Benedito. Oficinas como estratégia de pesquisa: Articulações teórico-metodológicas e aplicações ético-políticas. Psicologia \& Sociedade, v. 26, n. 1, p. 32-43, 2014. Disponível em: https://www.scielo.br/pdf/psoc/v26n1/05.pdf. Acesso em 25 ago. 2020.

THIESEN, Juares da Silva. Tempos e espaços na organização curricular: uma reflexão sobre a dinâmica dos processos escolares. Educação em Revista, v. 27, n. 1, p. 241-260, 2011. Disponível em: https://www.scielo.br/pdf/edur/v27n1/v27n1a11.pdf. Acesso em 25 ago. 2020.

VOLOCHÍNOV, Valentin. A construção da enunciação e outros ensaios. São Carlos: Pedro \& João Editores, 2013a.

VOLOCHÍNOV, Valentin. A construção da enunciação. In: VOLOCHÍNOV, Valentin. (Org.). A construção da enunciação e outros ensaios. São Carlos: Pedro \& João Editores, 2013b. p. 157-188.

VOLÓCHINOV, Valentin. Marxismo e filosofia da linguagem: problemas fundamentais do método sociológico na ciência da linguagem. São Paulo: Editora 34, 2017.

YOSETAKE, Ana Luiza et. al. Estresse percebido em graduandos de enfermagem. Rev. Eletrônica Saúde Mental Álcool Drog., v. 14, n. 2, p. 117-124, 2018. Disponível em: http://pepsic.bvsalud.org/pdf/smad/v14n2/08.pdf. Acesso em 25 ago. 2020. 
ZANELLA, Andréa Vieira. Fotografia e pesquisa em psicologia: retratos de alguns (des)encontros. In: ZANELLA, Andréa Vieira; TITTONI, Jaqueline (Org.). Imagens no pesquisar: experimentações. Porto Alegre: Ed. Dom Quixote, 2011. p. 15-33.

ZANELLA, Andréa Vieira. Decerto a fotografia é brincadeira...: Fotomontagem, fotointervenção, fotocriação. In: TITTONI, Jaqueline; ZANELLA, Andréa Vieira (Org.). Psicologia e Fotografia: alguns ensaios. Rio de Janeiro: Multifoco, 2016. p. 39-58. 